\title{
EN LAS ANTÍPODAS DEL TRABAJO DECENTE: EL TRABAJO FORZOSO
}

\author{
At the antipodes of Decent Work: Forced Labor
}

\author{
Tania García Sedano \\ Universidad Pontificia Comillas, Madrid
}

\section{ABSTRACT}

La Agenda para el desarrollo para después de 2015 fue aprobada por la Asamblea General de Naciones Unidas y dentro de la misma se incardinan los 17 Objetivos de Desarrollo Sostenible.

El octavo objetivo de desarrollo sostenible tiene por rubrica: "Promover el crecimiento económico sostenido, inclusivo y sostenible, el empleo pleno y productivo y el trabajo decente para todos».

El reverso del trabajo decente está representado por el trabajo forzoso. El trabajo forzoso es una flagrante violación de derechos humanos y en muchos casos un delito. Asi, se hace preciso aproximarnos a este fenómeno para diagnosticar su incidencia en nuestras sociedades y adoptar cuantas medidas sean necesarias para acabar con ese execrable fenómeno.

Palabras clave: Objetivo de Desarrollo Sostenible, Trabajo Decente, Trabajo Forzoso, España. 
The Agenda for development for after 2015 was approved by the General Assembly of the United Nations and within it the 17 Sustainable Development Goals are included.

The eighth objective of sustainable development has as its headline: "Promote sustained, inclusive and sustainable economic growth, full and productive employment and decent work for all».

The reverse of decent work is represented by forced labor. Forced labor is a flagrant violation of human rights and in many cases a crime. Thus, it is necessary to approach this phenomenon to diagnose its incidence in our societies and adopt whatever measures are necessary to put an end to this execrable phenomenon.

Keywords: Sustainable development goal, Decent Labour, Forced Labour, Spain. 


\section{SUMARIO}

1. Introducción. 2. Los Objetivos de Desarrollo Sostenible. 2.1. El Trabajo Decente Objetivo de Desarrollo Sostenible. 3. El Trabajo forzoso y El Trabajo decente. 3.1. El Trabajo forzoso en el ordenamiento jurídico español. 3.2. Concepto de Trabajo Forzoso. a) Trabajo o Servicio Exigido a un individuo. b) Amenaza de una pena cualquiera. c) Voluntariedad. d) Remuneración g) Duración. 3.3. Cifras de Trabajo Forzoso en España. 3.4. Medidas para erradicar el Trabajo Forzoso. 4. Conclusiones. 5. Bibliografía.

\section{Introducción}

El Preámbulo de la Constitución de la Organización Internacional del Trabajo (OIT 1919), en adelante OIT, ya estableció de forma nítida los objetivos de la Organización, cuyo centenario va a celebrarse: "Considerando que la paz universal y permanente sólo puede basarse en la justicia social; Considerando que existen condiciones de trabajo que entrañan tal grado de injusticia, miseria y privaciones para gran número de seres humanos, que el descontento causado constituye una amenaza para la paz y armonía universales; y considerando que es urgente mejorar dichas condiciones (...)».

Siguiendo esa senda, la Agenda 2030 de Naciones Unidas sitúa el trabajo decente para todos en el centro de las políticas para un desarrollo y un crecimiento sostenible e inclusivo que garantice la paz permanente.

El presente trabajo abordará el trabajo forzoso como antítesis del trabajo decente y desde ese prisma analizará la situación y obligaciones que dimanan para nuestro país.

\section{Los objetivos de desarrollo sostenible}

La Agenda para el desarrollo para después de 2015 fue aprobada por la Asamblea General de Naciones Unidas y dentro de la misma se incardinan los $17 \mathrm{Ob}$ jetivos de Desarrollo Sostenible y las 169 metas, conexas, de carácter integrado e indivisible (NU, 2015:2) que pretenden hacer realidad los derechos humanos de todas las personas y alcanzar la igualdad entre los géneros y el empoderamiento 
de todas las mujeres y nińas. Para ello ambos conjugan las tres dimensiones del desarrollo sostenible: económica, social y ambiental (NU, 2015: 2).

Los nuevos Objetivos y metas entraron en vigor el 1 de enero de 2016 y tiene por objetivo guiar las decisiones a adoptar durante los próximos 15 años (NU, 2015: 2).

Así, el trabajo decente se ha convertido en un objetivo universal y ha sido integrado en las más importantes declaraciones de derechos humanos, las Resoluciones de la ONU y los documentos finales de las principales conferencias, incluyendo el Artículo 23 de la Declaración Universal de los Derechos Humanos (1948), la Cumbre Mundial sobre desarrollo social (1995), el Documento de la Cumbre mundial (2005), el segmento de alto nivel de ECOSOC (2006), la Segunda década de las Naciones Unidas para la erradicación de la pobreza (20082017), la Conferencia sobre el desarrollo sostenible (2011) y en la Agenda 2030 para desarrollo sostenible de las Naciones Unidas (2015).

El concepto de trabajo decente, fue adoptado por la OIT, en su 87 reunión celebrada en el ańo 1999, en el contexto del Programa de Trabajo Decente (OIT, 1999: 4) por el que se comprometió a promover condiciones que generen oportunidades para que mujeres y hombres puedan conseguir un trabajo digno y productivo en condiciones de libertad, seguridad, equidad y dignidad humana. Así, el trabajo decente como concepto cimentado en los principios y derechos fundamentales en el trabajo, conlleva erradicar las distintas manifestaciones de pobreza y posibilitar la realización personal de los ciudadanos a través del trabajo (OIT, 1999: 4).

Cuando se presentó por primera vez el concepto de trabajo decente, éste fue definido como: "el trabajo productivo en condiciones de libertad, equidad, seguridad y dignidad, en el cual los derechos son protegidos y que cuenta con remuneración adecuada y protección social ${ }^{\prime}$ (LÓPEZ, 2016: 16).

Según la OIT (ANKER 2002:11), las características del trabajo decente más comúnmente señaladas por los trabajadores son: 1. Oportunidades de Trabajo 2. Trabajo Aceptable 3. Remuneración adecuada y trabajo productivo 4. Jornada laboral decente 5. Estabilidad y seguridad del empleo 6. Trato justo en la contratación y trabajo 7. Ambiente de trabajo seguro 8. Protección social 9. Balance del trabajo con la vida familiar 10. Diálogo social.

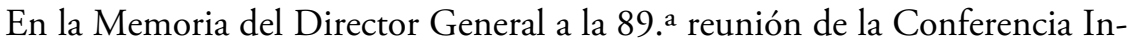
ternacional del Trabajo, en 2000, se presentó una nueva metodología en la que el trabajo decente debe entenderse como un concepto integrador, en cuya realización es necesario combinar aspectos relativos a los derechos, el empleo, la pro- 
tección y el diálogo en un todo; además, debe constituir una meta, un marco para la definición y la actuación de políticas, un método de organización de actividades y programas, y una plataforma para la asociación con otras entidades (OIT, 1999: 4).

Actualmente, la finalidad primordial de la OIT es promover oportunidades para que los hombres y las mujeres puedan conseguir un trabajo decente y productivo en condiciones de libertad, equidad, seguridad y dignidad humana.

\subsection{El Trabajo Decente Objetivo de Desarrollo Sostenible}

El octavo objetivo de desarrollo sostenible tiene por rubrica: "Promover el crecimiento económico sostenido, inclusivo y sostenible, el empleo pleno y productivo y el trabajo decente para todos».

El citado objetivo supone, por lo que a efectos del presente trabajo nos conlleva, las siguientes obligaciones (DAHRAM, 2013: 125): "Adoptar medidas inmediatas y eficaces para erradicar el trabajo forzoso, poner fin a las formas modernas de esclavitud y la trata de seres humanos y asegurar la prohibición y eliminación de las peores formas de trabajo infantil, incluidos el reclutamiento y la utilización de niños soldados, y, a más tardar en 2025, poner fin al trabajo infantil en todas sus formas».

Ghai (2012: 138) contempla el trabajo decente como un mecanismo que promueve los derechos y la seguridad del trabajo y elabora indicadores del trabajo decente (MATEOS 1997: 202-204) en varias áreas, destacando en este trabajo, el área vinculada a los derechos fundamentales y, en concreto, aquello vinculado con el trabajo forzoso y la trata de seres humanos.

Dentro del trabajo decente como objetivo de desarrollo sostenible se encuentran la proscripción del trabajo forzoso, formas contemporáneas de esclavitud, trata de seres humanos y peores formas de trabajo infantil.

\section{El trabajo forzoso y el trabajo decente}

El trabajo forzoso constituye la antítesis del trabajo decente. Así, para la consecución del objetivo de desarrollo sostenible consistente en el trabajo decente se hace preciso que se adopten políticas eficaces e inmediatas para erradicar el trabajo forzoso así como otras formas contemporáneas de esclavitud y la trata de seres humanos. Asimismo, se hace esencial asegurar la prohibición y eliminación de las peores formas de trabajo infantil, incluidos el reclutamiento y la utilización de niños soldados.

Para garantizar la consecución del meritado objetivo se hace preciso dar una respuesta adecuada a las cuestiones, ¿qué es el trabajo forzoso?, ¿qué prevalen- 
cia tiene en nuestro país? y, por supuesto, ¿qué medidas deben adoptarse para su erradicación.

\subsection{El Trabajo forzoso en el ordenamiento jurídico español}

España se mantuvo fuera de la Organización Internacional del Trabajo entre 1942 y 1956 (MATEOS, 1997: 202). Ello obedece a la imposición del trabajo forzoso como medida de cumplimiento y de redención en el régimen totalitario precedente.

En nuestro texto Constitucional no encontramos más referencia al trabajo o servicio forzoso que la prevista en el artículo 25 párrafo 2 de la Constitución (CANOSA, 2005: 134) que establece la proscripción del mismo en el ámbito penitenciario ${ }^{2}$.

De manera implícita el artículo 35 de la Constitución (LÓPEZ RUBIA, 2014: 113) se refiere a esta materia cuando establece: "Todos los españoles tienen el deber de trabajar y el derecho al trabajo, a la libre elección de profesión u oficio, a la promoción a través del trabajo y a una remuneración suficiente para satisfacer sus necesidades y las de su familia, sin que en ningún caso pueda hacerse discriminación por razón de sexo. La ley regulará un estatuto de los trabajadores».

Canosa ( 2005: 140), en relación con el trabajo forzoso y su proscripción por el artículo 4 del Convenio Europeo de Derechos Humanos, establece que ningún derecho laboral se halla en él pero se presupone que la libertad de trabajar se desenvuelve en condiciones laborales dignas, compatibles con la dignidad.

2 Artículo 25 párrafo 2:" Las penas privativas de libertad y las medidas de seguridad estarán orientadas hacia la reeducación y reinserción social y no podrán consistir en trabajos forzados. El condenado a pena de prisión que estuviere cumpliendo la misma gozará de los derechos fundamentales de este Capitulo, a excepción de los que se vean expresamente limitados por el contenido del fallo condenatorio, el sentido de la pena y la ley penitenciaria. En todo caso, tendrá derecho a un trabajo remunerado y a los beneficios correspondientes de la Seguridad Social, así como al acceso a la cultura y al desarrollo integral de su personalidad».

Sobre esta cuestión no abunda jurisprudencia, no obstante hemos de destacar la Sentencia del Tribunal Constitucional de fecha 20 de mayo de 2002, STC 116/92, que versa: "Aunque en la demanda no se desarrolle, debe entenderse que la primera de las alegaciones parte de la comprensión de que no puede constituir infracción la negativa a realizar un trabajo que se considera "forzado", porque tal tipificación sería contraria a la Constitución, lo que permite subsumir esta denuncia en la vulneración del art. 25.2 CE. Pues bien, esta alegación no tiene tampoco fundamento; se afirma en la demanda que del art. 25.2CE se deduce que el trabajo en prisión es un derecho del interno, no una obligación, y que lo contrario será tanto como admitir los trabajos forzados, prohibidos por el precepto constitucional. Frente a ello cabe decir que lo que la Administración penitenciaria exigió al recurrente fue, sencillamente, la limpieza que por turno le correspondía de parte de las zonas comunes de su módulo, prestación contemplada en el art. 29 de la Ley Orgánica general penitenciaria. Parece obvio insistir en que la prestación solicitada al recurrente de realizar la limpieza de parte de las zonas comunes de su módulo que por turno le correspondía no puede ser considerada, a los efectos del art. $25.2 \mathrm{CE}$, como un "trabajo forzoso". La negativa a su cumplimiento fue lo que fundamentó la sanción impuesta». 
Tutela la libertad de trabajar en una sociedad en la que se ha proscrito el trabajo forzoso.

En desarrollo de la prescripción referida a la aprobación de un Estatuto de los Trabajadores se aprobó el Real Decreto Legislativo 1/1995, de 24 de marzo, por el que se aprueba el texto refundido de la Ley del Estatuto de los Trabajadores (Doctrinalmente, MERCADER, 2015: 134; RAMÍREZ, 2015: 104; RODRÍGUEZ-PIÑERO 2011: 3) cuyo artículo 1 párrafo 1 establece: «La presente Ley será de aplicación a los trabajadores que voluntariamente presten sus servicios retribuidos por cuenta ajena y dentro del ámbito de organización y dirección de otra persona, física o jurídica, denominada empleador o empresario".

Desde otro prisma, en relación con la configuración de nuestro país, ex artículo 1 párrafo 1 de la Constitución" España se constituye en un Estado social y democrático de Derecho, que propugna como valores superiores de su ordenamiento jurídico la libertad, la justicia, la igualdad y el pluralismo político". El Tribunal Europeo de Derechos Humanos ha declarado que el valor del derecho a no ser sometido a trabajos forzados, constituye uno de los valores esenciales de una sociedad democrática y por ello no permite restricción de ningún tipo 3 .

Desde una aproximación jurídico penal, el trabajo forzoso constituye una de las finalidades del delito de trata de seres humanos. Así, el artículo 177 bis párrafo 1 apartado a) del Código Penal tipifica (VILLACAMPA, 2017: 457; SKUJUL, 2015: 198) como finalidad del delito de trata: «La imposición de trabajo o de servicios forzados".

En el ámbito regional europeo, el Tribunal Europeo de Derechos Humanos, en el asunto Van der Mussele contra Bélgica ${ }^{4}$, al constatar que el artículo 4 párrafo 2 del Convenio Europeo de Derechos Humanos pese a prohibir el trabajo forzoso ${ }^{5}$ no proporciona una definición del concepto de trabajo forzoso, consideró que los Travaux Préparatoires no eran idóneos para esclarecerlo. Por

3 Sentencia del Tribunal Europeo de Derechos Humanos ,asunto Soering c. Reino Unido de fecha 7 de julio de 1989. n. ${ }^{\circ}$ 14038/88.Párrafo 88.Sentencia del Tribunal Europeo de Derechos Humanos ,asunto Chahal c. Reino Unido, de fecha 13 de noviembre de 1996. Demanda n. ${ }^{\circ}$ 22414/93. Párrafo 79. Sentencia del Tribunal Europeo de Derechos Humanos, asunto Selmani c. Francia, de fecha 28 de julio de 1999. Demanda n.o 25802/1994.p. 79.

4 Sentencia Tribunal Europeo de Derechos Humanos, Van der Mussele c. Bélgica, de fecha de 23 de noviembre de 1983. Demanda n. ${ }^{\circ}$ 8919/80.Párrafo 32: "There is in fact a striking similarity, which is not accidental, between paragraph 3 of Article 4 (art. 4-3) of the European Convention and paragraph 2 of Article 2 of Convention No. 29. Paragraph 1 of the last-mentioned Article provides that "for the purposes" of the latter Convention, the term "forced or compulsory labour" shall mean "all work or service which is exacted from any person under the menace of any penalty and for which the said person has not offered himself voluntarily". This definition can provide a starting-point for interpretation of Article 4 (art. 4) of the European Convention."

5 Sentencias Tribunal Europeo de Derechos Humanos, caso, Stummer vs Austria, de fecha 7 de julio de 2011. Demanda n. ${ }^{\circ}$ 37452/02 . Párrafo 117. 
ello, tomó como punto de partida la definición contenida en la Convención n. ${ }^{\circ} 29$ de la Organización Internacional del Trabajo. De este modo y como ya había hecho en otras ocasiones ${ }^{6} y$ con otros textos, el Tribunal Europeo de Derechos Humanos subrayó que el Convenio n. ${ }^{\circ} 29$ es un instrumento vivo y por lo tanto debe ser interpretado de manera dinámica.

\subsection{Concepto de trabajo forzoso}

El artículo segundo párrafo 1 del Convenio 29 de la Organización Internacional del Trabajo relativo al trabajo forzoso u obligatorio establece: "A los efectos del presente Convenio, la expresión 'trabajo forzoso u obligatorio' designa todo trabajo o servicio exigido a un individuo bajo la amenaza de una pena cualquiera y para el cual dicho individuo no se ofrece voluntariamente».

Por su parte, ni el Protocolo del 2014 ni el Convenio n. ${ }^{\circ} 105$ proporcionan una definición del trabajo forzoso u obligatorio, legitima la definición contenida en el Convenio n. ${ }^{\circ} 29$ (OIT, 1968: 42), si no que exige la abolición de toda forma de trabajo forzoso u obligatorio los supuestos enumerados en su artículo 1.

\section{a) Trabajo o Servicio}

Por trabajo o servicio se entenderá todo tipo de trabajo, servicio y empleo con independencia del sector de actividad, industria o sector en el que se desarrolle. En el mismo sentido, será indiferente si tiene lugar en la economía formal o informal (EUROPEAN COURT OF HUMAN RIGHTS, 2014: 22).

Como ya estableció la Comisión de Derechos Humanos (OIT, 1979: 20) la imposición de un trabajo o servicio no puede ser equiparada a los supuestos en los que lo que se impone es la obligación de seguir una enseñanza o formación. Así, no puede obviarse que la enseñanza obligatoria se reconoce, en diversas normas internacionales y también se contempla en los instrumentos de la Organización Internacional del Trabajo, como medio para garantizar el derecho a la educación.

\section{b) Exigido a un individuo}

Pese a que pudiera parecer una obviedad, el legislador utiliza una sinécdoque por cuanto que se refiere a los individuos como seres humanos - adultos y niños, y nacionales y extranjeros, incluidos los migrantes en situación irregular.

\footnotetext{
${ }^{6}$ Sentencias Tribunal Europeo de Derechos Humanos, Graziani-Weiss contra Austria de fecha 18 de noviembre de 2011. Demanda n. $31950 / 06$, y caso, Stummer vs Austria, de fecha 7 de julio de 2011, Demanda n. ${ }^{\circ}$ 37452/02 . Párrafo 118.
} 


\section{c) Amenaza de una pena cualquiera}

El Tribunal Europeo de Derechos Humanos ${ }^{7}$ ha considerado que el concepto de sanción comprende desde la violencia física hasta formas más sutiles de coerción de carácter psicológico, como la amenaza de denunciar a las víctimas a la policía o a las autoridades migratorias cuando su situación laboral es ilegal.

En cuanto a la amenaza de una sanción ésta se ha concretado por el Tribunal Europeo de Derechos Humanos casuísticamente. La Corte ha definido el concepto amenaza ${ }^{8}$, estableciendo que el criterio para determinar si esta ha existido es de índole subjetiva, es decir aparece supeditado a la percepción de la víctima y no tanto a la existencia de una sanción.

\section{d) Voluntariedad}

La expresión se ofrece voluntariamente refiere al consentimiento libre e informado de los trabajadores para prestar el consentimiento en el contexto de una relación de trabajo y a su libertad para rescindir la relación laboral en cualquier momento (LÓPEZ RODRÍGUEZ, 2018: 392).

Así, la presencia de una amenaza cualquiera, que constituye uno de los elementos para determinar la existencia de trabajo forzoso determina la nulidad del consentimiento prestado por una víctima de trabajo forzoso. Según el Tribunal Europeo de Derechos Humanos, el adjetivo obligatorio no puede abarcar cualquier obligación jurídica, por ejemplo las obligaciones que derivan de la suscripción de un contrato, sino que debe tratarse de una obligación que provenga de una amenaza o pena y que, por tanto, es contraria a la voluntad del individuo?.

7 Sentencia Tribunal Europeo de Derechos Humanos, C.N. et V. c. France, de fecha 11 octubre 2012, Demanda n. ${ }^{\circ}$ 67724/09. Párrafo 77.

8 Sentencia Tribunal Europeo de Derechos Humanos Siliadin vs Francia, de fecha 26 de Julio de 2005, Demanda n. ${ }^{\circ}$ 73316/01. Párrafo 117: "It remains to be ascertained whether there was "forced or compulsory" labour. This brings to mind the idea of physical or mental constraint. What there has to be is work "exacted ... under the menace of any penalty" and also performed against the will of the person concerned, that is work for which he "has not offered himself voluntarily".

9 Sentencia Tribunal Europeo de Derechos Humanos, Van der Mussele c. Bélgica, demanda n. ${ }^{\circ}$ 8919/80, sentencia de fecha de 23 de noviembre de 1983. Párrafo 34: «It remains to be ascertained whether there was "forced or compulsory» labour. The first of these adjectives brings to mind the idea of physical or mental constraint, a factor that was certainly absent in the present case. As regards the second adjective, it cannot refer just to any form of legal compulsion or obligation. For example, work to be carried out in pursuance of a freely negotiated contract cannot be regarded as falling within the scope of Article 4 on the sole ground that one of the parties has undertaken with the other to do that work and will be subject to sanctions if he does not honour his promise. [...] What there has to be is work "exacted ... under the menace of any penalty» and also performed against the will of the person concerned, that is work for which he "has not offered himself voluntarily". 
La sentencia del Tribunal Europeo de Derechos Humanos caso Chowdury y Otros c. Grecia ${ }^{10}$ se juzgan unos hechos en los que la ausencia de voluntariedad es palmaria. Se trata de cuarenta y dos demandantes, nacionales de Bangladesh, inmigrantes en situación administrativa irregular carentes de permiso de trabajo, que rabajaban de 7 a 19 horas cada día recogiendo fresas «bajo la vigilancia de guardias armados» contratados por los empleadores para los que aquellos prestaban sus servicios Vivían en tiendas de cartón, nylon y bambú en los que «no habia ni baños ni agua corriente y hacía tanto calor que la piel se fundia». A pesar de que los trabajadores reclamaron sus salarios, los empleadores se negaron a pagarles por el trabajo desarrollado. Esta situación provocó la huelga de los trabajadores en tres ocasiones durante el primer cuatrimestre de 2013 en reivindicación de sus derechos económicos. Para eludir las consecuencias de la huelga, los empleadores en abril del año 2013 llevaron a los campos de fresas a una nueva cuadrilla trabajadores migrantes de Bangladesh. Esta circunstancia significó un fuerte enfrentamiento entre los huelguistas y sus empleadores, produciéndose un tiroteo por parte de un guardia armado contra los trabajadores.

\section{e) Remuneración}

Si bien la existencia de una remuneración facilita la consideración del trabajo como voluntario, el carácter de forzoso del trabajo no depende del carácter retribuido o gratuito del trabajo (SARRASOLA 2004:84).

En ese sentido, no se ha constatado vulneración del artículo 4 en los casos en que el trabajador no recibía remuneración por el trabajo realizado pero el trabajo se realizaba voluntariamente y el derecho al pago no era objeto de controversia (EUROPEAN COURT OF HUMAN RIGHTS. 2014: 30).

\section{f) Duración}

Al trabajo forzoso u obligatorio se le ha asignado, generalmente, un carácter temporal u ocasional, sin que ello suponga un período de sometimiento breve ${ }^{11}$.

\section{3.. Cifras de Trabajo Forzoso en España}

La Relatora Especial de Naciones Unidas sobre Formas Contemporáneas de Esclavitud (SHANINIAN, 1999: 14), incluidas sus causas y consecuencias, estima que actualmente en el mundo existen 27 millones de personas que son víctimas de alguna de las formas contemporáneas de esclavitud, entre las que se incluyen el trabajo forzoso y la servidumbre.

10 Sentencia Tribunal Europeo de Derechos Humanos, caso Chowdury y Otros c. Grecia, de fecha 30 de marzo de 2017. Demanda n. ${ }^{\circ} 21884 / 15$.

11 Sentencia Tribunal Europeo de Derechos Humanos Siliadin vs Francia, de fecha 26 de Julio de 2005, Demanda n. ${ }^{\circ}$ 73316/01. Párrafo 94. 
Por su parte, la Organización Internacional del Trabajo estima que en el año 2017 hay cuarenta millones de personas sometidas a formas contemporáneas de esclavitud (OIT, 2017: 5).

De conformidad con el Índice Mundial de Esclavitud correspondiente al año 2014 (GLOBAL SLAVERY INDEX, 2014: Spain) sobre 167 países, España tendría una estimación de 6.100 personas viviendo alguna forma de moderna esclavitud, el 0,013\% de su población.

A la fecha carecemos de cualquier dato sobre este fenómeno, circunstancia que no hace si no agravar la situación de las víctimas de esta flagrante violación de derechos humanos.

La única aproximación que disponemos se encuentra en las Diligencias de seguimiento de la Fiscalía General del Estado (FISCALÍA GENERAL DEL ESTADO, 2017: 528). La Memoria de la misma establece que han sido objeto de especial seguimiento 85 causas por delito de trata de seres humanos: 8 con fines de explotación laboral, 2 con fines de mendicidad, 2 con fines de matrimonio forzosos y 3 con fines de cometer actividades delictivas.

En el caso de trata con fines de explotación laboral se han localizado $15 \mathrm{mu}-$ jeres (dos de ellas menores de edad) y 71 hombres víctimas de este delito. Provienen de 6 países distintos, destacando 72 búlgaros (61 hombres y 11 mujeres). Por este delito están siendo investigados 24 individuos (19 hombres y 5 mujeres) de 7 nacionalidades.

\subsection{Medidas para erradicar el Trabajo Forzoso}

Recientemente, España ha ratificado (BOE, 2017: 309) el Protocolo de 2014 sobre Trabajo Forzoso de la Organización Internacional del Trabajo que complementa el Convenio sobre trabajo forzoso de 1930.

La Unión Europea había aprobado la Resolución legislativa del Parlamento Europeo por la que se autoriza a los Estados miembros a ratificar, en interés de la Unión Europea, el Protocolo de 2014 del Convenio relativo al trabajo forzoso u obligatorio, 1930, de la Organización Internacional del Trabajo, en adelante el Protocolo, en lo que respecta a las cuestiones relativas a la política social y la Decisión (UE) 2015/2071 del Consejo de 10 de noviembre de 2015 por la que se autoriza a los Estados miembros a ratificar, en interés de la Unión Europea, el Protocolo de 2014 del Convenio relativo al trabajo forzoso u obligatorio, 1930, de la Organización Internacional del Trabajo, en lo que respecta a las cuestiones relativas a la cooperación judicial en materia penal (PARLAMENTO EUROPEO, 2015. 36).

La ratificación del Protocolo supone la asunción de obligaciones internacionales que entrarán en vigor en los doce meses siguientes a la fecha en que las ratificaciones de los Miembros hayan sido registradas por el Director Gene- 
ral. Artículo 8 párrafo 2 y la ratificación por España del Protocolo fue registrada en fecha 20 de septiembre de 2017 por lo que entrará en vigor el día 20 de septiembre de 2018.

Las obligaciones derivadas del Protocolo pueden sistematizarse en tres áreas, que identificaremos con la Prevención, Persecución y Protección de las víctimas y que, según el propio Protocolo deberán imbricarse en una Política y un Plan Nacionales.

Ya que el Protocolo entrará en vigor en Septiembre de este año, instamos a las autoridades nacionales a dar cumplimiento de las obligaciones contraídas internacionalmente junto con todas aquéllas que sean precisas para la erradicación de este fenómeno.

\section{Conclusiones}

Se hace urgente la adopción de las medidas que permitan dar cumplimiento a las obligaciones internacionalmente asumidas por nuestro país en materia de trabajo forzoso. A la sazón nos encontramos ante un Objetivo de Desarrollo Sostenible y ante un Protocolo de 2014 ratificado por España.

Para ello, la OIT en el Protocolo de 2014 insta a la adopción de las mismas de forma tripartita y partiendo de un adecuado conocimiento de la incidencia de este fenómeno en la sociedad que pretenda implementarlo.

\section{Bibliografía}

Anker, R. et al., Measuring Decent Work with Statistical Indicators, Statistical Development and Analysis Unit, Policy Integration Department, ILO. 2002.

Canosa Usera, R., La prohibición de la esclavitud y del trabajo forzado: un ejemplo de integración entre Tratados Internacionales» en García Roca, J. Santolaya, P. (coords.) La Europa de los Derechos. Centro de Estudios Políticos y Constitucionales, Madrid, 2005.p. 134.

Dahram, G. "Trabajo decente. Conceptos e indicadores», en Revista Internacional del Trabajo, vol. 2, 2. 2013. p. 125-160. Dahram, G. «Decent work: universality and diversity» in IILS 159. 2005.

European Court Of Human Rights, Guide on Article 4 of the European Convention on Human Rights: Prohibition of slavery and forced labour.2nd edition, Strasbourgh. 2014. Párrafo 30.

Fiscalía General del Estado, Memoria de la Fiscalía General del Estado de 2017. Madrid, 2017.

GhaI, D. «Trabajo decente. Concepto e indicadores» en Revista Internacional del Trabajo, vol. 122-2003, núm. 2. 
Walk Free Foundation, Global Slavery Index, 2014. Disponible en línea: http:// d3mj66ag90b5fy.cloudfront.net/wpcontent/uploads/2014/11/Global_Slavery_ Index_2014_final_lowres.pdf

Iglesias SkUlJ, A. «De la trata de seres humanos: artículo 177 bis CP» en González Cussac, J.L (dir.) Comentarios a la Reforma Penal de 2015. Tirant lo Blanch, Valencia, 2015.

López Rodríguez, J., "Trabajo forzado u obligatorio: El significado contemporáneo de un viejo fenómeno a la luz de la jurisprudencia del Tribunal Europeo de Derechos Humanos» en Revista General de Derecho del Trabajo y de la Seguridad Social n. ${ }^{\circ}$ 7, 2018. p.392.

López Rubia, M.E.. "Prohibición de la esclavitud y del trabajo forzoso» en Ordeñana Gezuraga, Ixusko (dir.). La carta de los derechos fundamentales de la Unión Europea y su reflejo en el ordenamiento jurídico español. Thomson Reuters, Cizur Menor. 2014.

Mateos, A., "El retorno de España a la organización internacional del trabajo: La persistencia del ostracismo, 1956-1960» en Revista de Historia Contemporánea n. ${ }^{\circ} 16.1997$.

Mercader Uguina, J.R., Lecciones de Derecho del Trabajo. Tirant lo Blanch, Valencia, 2015.p.134.

Naciones Unidas. Asamblea General, Proyecto de documento final de la cumbre de las Naciones Unidas para la aprobación de la agenda para el desarrollo después de 2015. Documento: A/69/L.85. Párrafo 18.

OIT, El trabajo forzoso, Estudio general de 1968. Párrafo 42.

OIT, Memoria del Director General a la 87. ${ }^{a}$ reunión de la Conferencia Internacional del Trabajo. Trabajo decente. Ginebra. 1999.

OIT, Memoria del Director General a la 89. a reunión de la Conferencia Internacional del Trabajo. «Reducir el déficit de trabajo decente. Un desafío global». Ginebra. Párrafos 1.1 y 3.5 .

OIT, Global estimates of modern slavery, forced labour and forced marriage. Geneva, 2017.

Parlamento Europeo. Lochbihler, B., Comisión de Asuntos Exteriores. Subcomisión de Derechos Humanos. Proyecto de informe sobre la lucha contra el tráfico de seres humanos en las relaciones exteriores de la UE (2015/2340(INI)) .Párrafo 36.

Proyecto de recomendación sobre el proyecto de Decisión del Consejo, Documento 06732/2015 - C8-0079/2015 - 2014/0259(NLE).

Ramírez Martínez, J.M., "Tema 4: El trabajador» en Camps Ruiz, L.M. Ramírez MarTínez, J.M. Derecho del Trabajo. Tirant lo Blanch, Valencia, 2015.

Rodríguez-Piñero y Bravo-Ferrer, M., "La libertad de trabajo y la interdicción del trabajo forzoso", en Relaciones laborales: Revista crítica de teoría y práctica, n. ${ }^{\circ}$ 1, 2011.

Sarrasola Gorriti, S. «El artículo 4: Prohibición de la esclavitud y del trabajo forzoso» en Lasagabaster Herrarte (dir.) Convenio Europeo de Derechos Humanos: Comentario Sistemático. Civitas, Cizur Menor. 2004.

Shaninian, G., Anotaciones a la agenda del $12 .^{\circ}$ periodo de sesiones del Consejo de Derechos Humanos. Documento: A/HRC/12/21.

Villacampa Estiarte, C., «El delito de trata de seres humanos en derecho penal español tras la reforma de 2015» en Perez Alonso, E. (dir.) El derecho ante las formas contemporáneas de esclavitud. Tirant lo Blanch, Valencia. 2017. 